\title{
Utilization of Photoconductive Gain in a-Si:H Devices for Radiation Detection
}

H. K. Lee, J. S. Drewery, W. S. Hong, T. Jing, S. N. Kaplan

and V. Perez-Mendez

Physics Division

Lawrence Berkeley Laboratory

University of California

Berkeley, CA 94720

May 1995

This work was supported by the Director, Office of Energy Research, Office of High Energy and Nuclear Physics, Division of High Energy Physics of the U. S. Department of Energy under Contract No. DE-AC03-76SF00098. 


\section{DISCLAIMER}

This report was prepared as an account of work sponsored by an agency of the United States Government. Neither the United States Government nor any agency thereof, nor any of their employees, make any warranty, express or implied, or assumes any legal liability or responsibility for the accuracy, completeness, or usefulness of any information, apparatus, product, or process disclosed, or represents that its use would not infringe privately owned rights. Reference herein to any specific commercial product, process, or service by trade name, trademark, manufacturer, or otherwise does not necessarily constitute or imply its endorsement, recommendation, or favoring by the United States Government or any agency thereof. The views and opinions of authors expressed herein do not necessarily state or reflect those of the United States Government or any agency thereof. 


\section{DISCLAIMER}

Portions of this document may be illegible in electronic image products. Images are produced from the best available original document. 


\title{
UTILIZATION OF PHOTOCONDUCTIVE GAIN IN a-Si:H DEVICES FOR RADIATION DETECTION
}

H. K. Lee, J. S. Drewery, W. S. Hong, T. Jing, S. N. Kaplan and V. Perez-Mendez Lawrence Berkeley Laboratory, Berkeley, CA 94720

\begin{abstract}
The photoconductive gain mechanism in a-Si: $\mathrm{H}$ was investigated in connection with applications to radiation detection. Various device types such as $p-i-n, n-i-n$ and $n-i-p-i-n$ structures were fabricated and tested. Photoconductive gain was measured in two time scales: one for short pulses of visible light $(<1 \mu \mathrm{sec})$ which simulates the transit of an energetic charged particle, and the other for rather long pulses of light ( $1 \mathrm{msec}$ ) which simulates $x$-ray exposure in medical imaging. We used two definitions of photoconductive gain: current gain and charge gain which is an integration of the current gain. We found typical charge gains of $3 \sim 9$ for short pulses and a few hundred for long pulses at a dark current level of $10 \mathrm{~mA} / \mathrm{cm}^{2}$. Various gain results are discussed in terms of the device structure, applied bias and dark current.
\end{abstract}

\section{INTRODUCTION}

The technology of radiation detection using a-Si:H $\mathrm{p}-\mathrm{i}-\mathrm{n}$ photodiodes has been extensively developed since its first experimental success about a decade ago.[1,2] Many applications of a-Si:H detectors in the detection of visible light, $x$-rays, $\gamma$-rays and charged particles have been investigated.[1-5] The basic principle involved in these previously reported radiation detection techniques is to measure the signal which is induced by the motion of charge carriers along the depletion field in a reverse biased $\mathrm{p}-\mathrm{i}-\mathrm{n}$ diode. The maximum number of carriers collected is equal to the number of photons which interact in the i-region of the diode, hence the maximum gain is unity. The photoconductive gain mechanisms in various a-Si:H devices such as metal-i-metal, $n-i-n, p-i-n$ and $n-i-p-i-n$ structures have been investigated, and photoconductive gains of more than 100 for the steady state photocurrent have been reported.[6-9] a-Si:H optical imaging devices utilizing this gain mechanism have been successfully made, which were based on Schottky diodes or $n-i-n$ devices which had coplanar or sandwich structures.[10-12] Using the transient behavior of the photoconductive gain mechanism, a signal gain in radiation detection with a-Si:H devices may be possible.

In this paper, the experimental results of the gain with a-Si:H $\mathrm{p}-\mathrm{i}-\mathrm{n}, \mathrm{n}-\mathrm{i}-\mathrm{n}$ and $n-i-p-i-n$ devices for rather short period of light pulses are discussed.

\section{EXPERIMENTAL}

Test samples were fabricated using our PECVD machine and all of the samples had sandwich structure. The thickness of the $\mathrm{i}$-layers were $1 \sim 30 \mu \mathrm{m}$ for $\mathrm{p}-\mathrm{i}-\mathrm{n}$ diodes, $1 \mu \mathrm{m}$ for the thick $\mathrm{i}$-layer of $\mathrm{n}-\mathrm{i}-\mathrm{p}-\mathrm{i}-\mathrm{n}$ diodes and $14 \mu \mathrm{m}$ for $\mathrm{n}-\mathrm{i}-\mathrm{n}$ samples. The thin $\mathrm{i}$-layer in the $\mathrm{n}-\mathrm{i}-\mathrm{p}-\mathrm{i}-\mathrm{n}$ diodes was about $30 \mathrm{~nm}$ thick, and the p-layer was about 15 $\mathrm{nm}$ thick and slightly doped ( $500 \mathrm{ppm}$ of diborane) to suppress the dark current without affecting the photoconductive gain mechanism by recombination of electrons in the $\mathrm{p}$-layer.[7] The $\mathrm{n}$ - and $\mathrm{p}$-layers of the $\mathrm{p}-\mathrm{i}-\mathrm{n}$ diodes were thick enough to prevent tunneling of electrons or holes in reverse biased condition, but thin enough to let the 


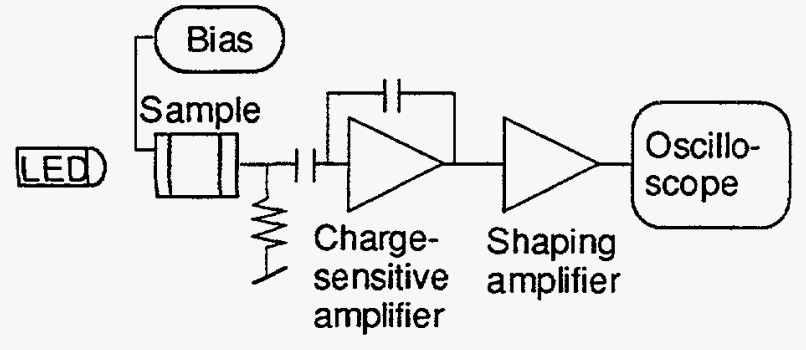

(a)

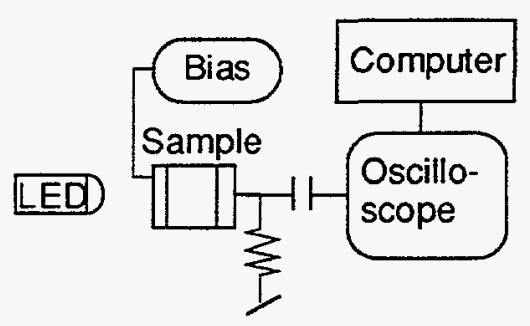

(b)

Fig. 1 Experimental system for photoconductive gain measurement. For the short LED pulse the conventional radiation measurement system (a) was used, and with a long LED pulse the photocurrent was directly read by the oscilloscope via AC coupling (b).

light pass through those. These layers provided ohmic contacts in forward bias which is essential for the photoconductive gain.

The measurements of photo-signals were performed in two different time scales. In order to simulate the transit of a fast charged particle, an LED of $0.2 \mu \mathrm{sec}$ pulse width was used, and for the simulation of x-ray exposure, $1 \sim 30 \mathrm{msec}$ of LED light was incident on the samples. The conventional experimental system for detecting a single particle was used for the short pulse measurement, and is shown in Fig. 1 (a). The gain of a $\mathrm{p}-\mathrm{i}-\mathrm{n}$ or $\mathrm{n}-\mathrm{i}-\mathrm{p}-\mathrm{i}-\mathrm{n}$ diode was calculated by dividing the photo-signal in forward bias by the maximum signal in reverse bias, which was also used to calculate the gain in $n-\mathrm{i}-\mathrm{n}$ device which had the same thickness and transparency as the corresponding $\mathrm{p}-\mathrm{i}-\mathrm{n}$ device. For the long pulse measurement, the photocurrents from the sample devices were directly measured as shown in Fig. 1 (b). Using AC coupling, the DC dark current could be separated from the photocurrent. The RC time constant of the system was made long enough to prevent decay of the photocurrent level. The measured photocurrent was integrated using a computer which is connected to the digital oscilloscope, and both current gain and charge gain were calculated by comparing the amplitude in forward bias and in reverse bias as in the short pulse measurements.

\section{RESULTS}

For a $1 \mathrm{msec}$ light pulse, the photocurrent obtained with a $14 \mu \mathrm{m}$ thick $\mathrm{p}-\mathrm{i}-\mathrm{n}$ diode is shown in Fig. 2. The photocurrent is normalized to the maximum value in reverse bias to show the gain. To achieve a unity gain in reverse bias, the detector bias should be higher than the depletion bias which is defined as the required reverse bias for full depletion of the i-region. More than $200 \mathrm{~V}$ was needed to obtain the unity gain in

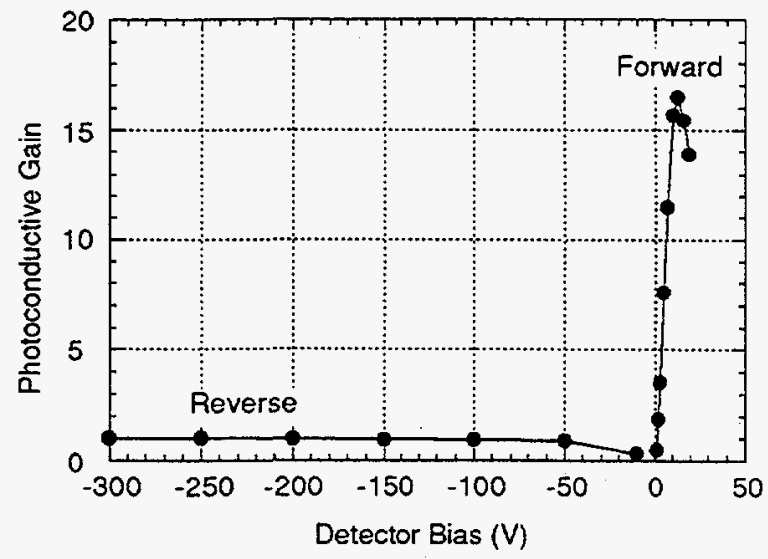

Fig. 2 The maximum photocurrent in a $14 \mu \mathrm{m}$ thick $p-i-n$ diode as a function of detector bias when $1 \mathrm{msec}$ of light is illuminated. 
reverse bias with this diode, while the unity gain could be achieved with about $1.5 \mathrm{~V}$ in forward bias. The photocurrent increased almost linearly with the applied forward bias and reached its maximum value of 17 at $13 \mathrm{~V}$; the gain decreased at higher forward bias as discussed in the next section.

For a $1 \mathrm{msec}$ light pulse, the current gain and charge gain of the same thickness $n-i-n$ device is compared with those of the p-i-n diode in Fig. 3 (a) and (b) as functions of the detector bias and dark current, respectively. At low biases both the current gain and charge gain in $p-i-n$ diode are higher than those of $n-i-n$, but at higher biases the gains of the $p-i-n$ diode decrease while those of the $n-i-n$ device keeps increasing and at $100 \mathrm{~V}$ the current gain is 110 and the charge gain is 260 with an integration time of 5 msec. While the gain behavior of the $\mathrm{p}-\mathrm{i}-\mathrm{n}$ and $\mathrm{n}-\mathrm{i}-\mathrm{n}$ devices are quite different when those are plotted as functions of bias as in Fig. 3 (a), they showed similar dependence on the dark current at low current level as shown in Fig. 3 (b). The current gain and charge gain of the $n-i-n$ device were found to proportional to $J_{d}{ }^{0.6}$, where $J_{d}$ is the dark current density. From these results, the photoconductive gain is mainly determined by the dark current rather than the applied bias, and at low dark currents, the gains of the $p-i-n$ and $n-i-n$ device of the same thickness were the same for the same dark current. The $n-i-p-i-n$ diodes showed similar gain behavior as the $n-i-n$ devices, because it is basically an $n-i-n$ device with a very slightly doped $p$-layer which is thin and located close to one end of the device, hence the overall properties are similar to the $n-i-n$ device except that it has the polarity of the operation bias, that is, if a negative bias is applied to the thin $\mathrm{i}$-layer side it is in reverse bias. The photocurrent of the $n-i-p-i-n$ diode in forward bias was also proportional to $J_{d}{ }^{0.6}$.

The gains of $14 \mu \mathrm{m}$ thick $\mathrm{p}-\mathrm{i}-\mathrm{n}$ and $\mathrm{n}-\mathrm{i}-\mathrm{n}$ devices for short light pulses $(0.2 \mu \mathrm{sec})$ are shown in Fig. 4 as functions of dark current with two different shaping amplifier integration times. Due to the long decay time of the photocurrent, longer integration time produced larger gains. For short light pulses, the behavior of the $p-i-n$ and $n-i-n$ devices were almost identical to each other for the same dark current. A similar behavior was also found with the $n-i-p-i-n$ diode. The maximum gains obtained with our best samples at a dark current density of $10 \mathrm{~mA} / \mathrm{cm}^{2}$ were 6 and 9 for integration times of $1 \mu \mathrm{sec}$ and $5 \mu \mathrm{sec}$, respectively.

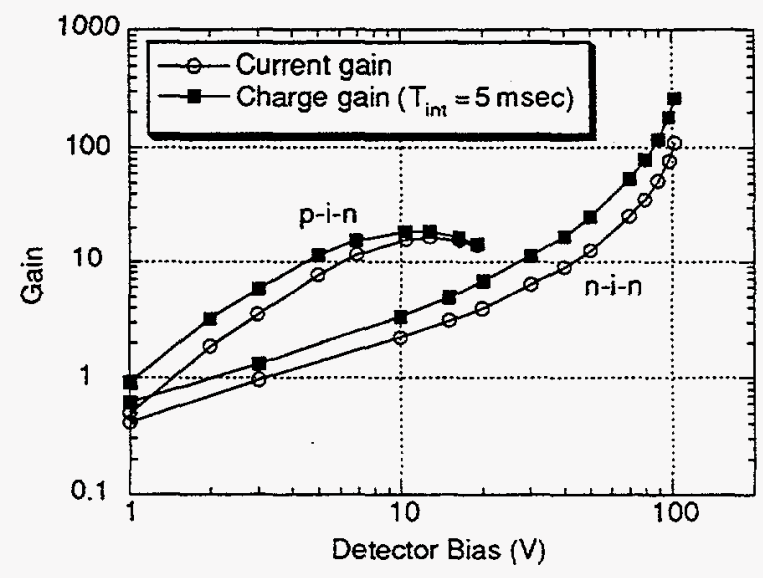

(a)

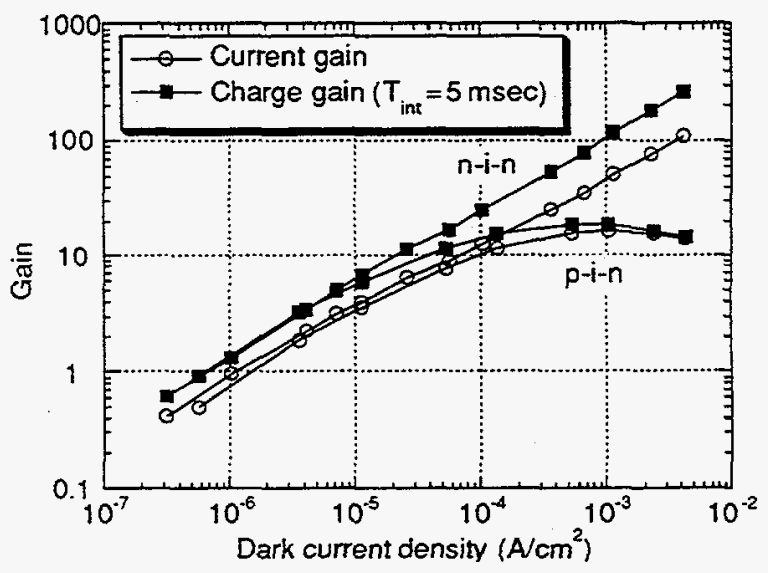

(b)

Fig. 3 Comparisons of the current gain and charge gain in $p-i-n$ diode and $n-i-n$ device. The thickness of the devices is $14 \mu \mathrm{m}$ and both of these have the same transparency. 


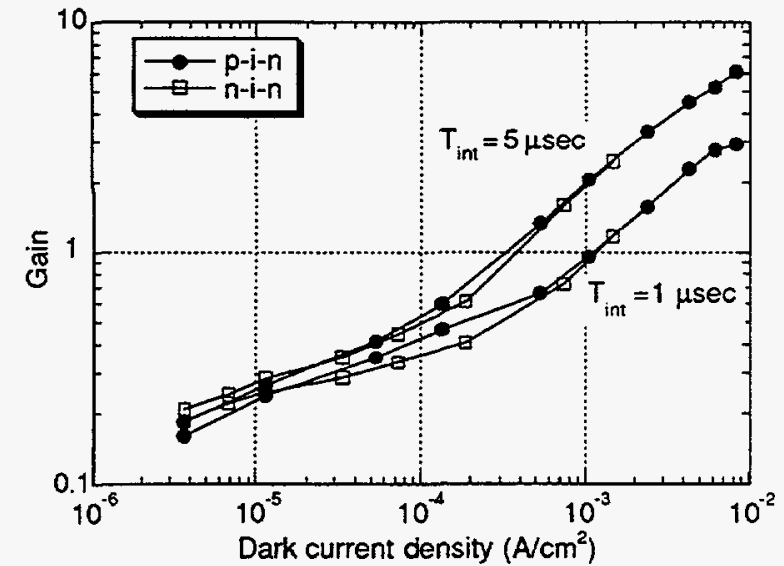

Fig. 4 The charge gains of $\mathrm{p}-\mathrm{i}-\mathrm{n}$ and $\mathrm{n}-\mathrm{i}-\mathrm{n}$ devices for $200 \mathrm{nsec}$ of light pulse. The integration time was controlled in the shaping amplifier.

\section{DISCUSSION}

For an insulator or a semiconductor with a single trap level, the transient photocurrent can be expressed as[13]

$$
\begin{array}{ll}
I_{p}(t)=q F d A G_{p}\left(1-e^{-t / \tau_{r}}\right) & \text { (rise), } \\
I_{p}(t)=q F d A G_{p} e^{-t / \tau_{r}} & \text { (decay), }
\end{array}
$$

where, $\mathrm{q}$ is the charge of an electron, $\mathrm{F}$ is the generation rate of photo-electrons per unit volume, $d$ is the thickness of the device, $A$ is the area, $G_{p}$ is the steady state photoconductive gain defined as $\tau / T_{r}, \tau$ is the lifetime of the majority carriers, $T_{r}$ is the transit time of the majority carriers across the device and $\tau_{r}$ is the response time which is defined as $\tau n_{t} / n_{f}$, where $n_{f}$ and $n_{t}$ is the free and trapped majority carrier density, respectively. Since a-Si:H has a distribution of trap levels in the forbidden gap, a single exponential term can not express the rise and decay shapes of the photocurrent, and multicomponent exponentials are needed to fit the shape of the time response.[14] For a-Si:H photoconductor, the transient photocurrent can be written as

$$
\begin{array}{ll}
I_{p}(t)=I_{\max }\left(1-\sum_{i} a_{i} e^{-t / \tau_{i}}\right) & \text { (rise), } \\
I_{p}(t)=I_{\max } \sum_{i} a_{i} e^{-t / \tau_{i}} & \text { (decay), }
\end{array}
$$

where $I_{\max }$ is the photocurrent at steady state, $\tau_{\mathrm{i}}$ is a response time which corresponds to the $i-$ th trap and $a_{i}$ is a weighting factor which represents the influence of the $i-t h$ trap to the photocurrent. The summation of $\mathrm{a}_{\mathrm{i}}$ is equal to 1 . In Fig. 5, the photocurrent shape with a 1 msec light pulse is shown with the curves fitted by Eq. (2), where $a_{i}$ and $\tau_{\mathrm{i}}$ were used as fitting parameters. In order to find the characteristics of the current decay, the photocurrents of $\mathrm{p}-\mathrm{i}-\mathrm{n}$ and $\mathrm{n}-\mathrm{i}-\mathrm{n}$ devices after a short pulse of light were measured and are compared in Fig. 6. At the same dark current density, the initial decay times of the $\mathrm{p}-\mathrm{i}-\mathrm{n}$ and $\mathrm{n}-\mathrm{i}-\mathrm{n}$ devices are almost identical, and this explains why their gains are almost the same for the short light pulses. At higher dark current levels (Fig. 6 (b)), the photocurrent of the $\mathrm{p}-\mathrm{i}-\mathrm{n}$ diodes decays faster than that of the $n-i-n$ devices for the longer time scales. To extract more information about decay times in the long time scales, the time $\left(\mathrm{T}_{30 \%}\right)$ taken to reach $30 \%$ of the peak photocurrent after $1 \mathrm{msec}$ of light exposure were measured with $\mathrm{p}-\mathrm{i}-\mathrm{n}$ and $\mathrm{n}-\mathrm{i}-\mathrm{n}$ devices and these are shown in 


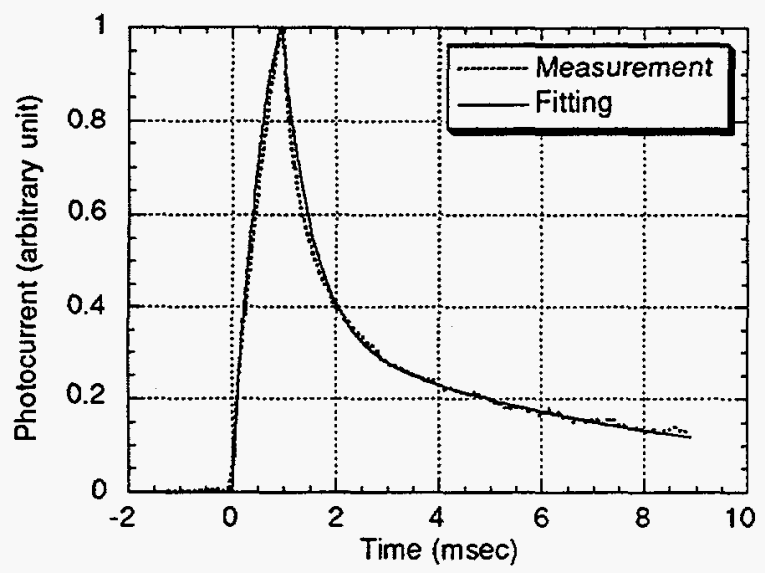

Fig. 5 The photocurrent shape of a $p-i-n$ diode with a $1 \mathrm{msec}$ light pulse. The current is normalized to the maximum current at $1 \mathrm{msec}$. $3 \mathrm{~V}$ of forward bias was applied. Eq. (2) was used to fit the measurement.

Fig. 7. The decay time of the $n-i-n$ increases linearly with the detector bias while that of the $\mathrm{p}-\mathrm{i}-\mathrm{n}$ decreases as the bias increases and is approximately proportional to the reciprocal of the detector bias. The decreasing decay time constant may be explained by the decrease of the electron lifetime in the $\mathrm{p}-\mathrm{i}-\mathrm{n}$ diode. As the forward bias increases, the dark current increases due to the increased number of electrons and holes by increased double injections from the contacts, and the quasi-Fermi levels of the electrons and holes move toward the band edges making the recombination centers broadened, hence more recombination of electrons and holes occurs and eventually the lifetime of the electrons decreases. Due to this decrease in the lifetime, the photocurrent of the $p-i-n$ diode decreases at high biases, since $I_{\max }$ in $\mathrm{Eq}$. (2) is proportional to the lifetime. At low biases, however, the decrease in the exponential terms with the bias is dominant, hence the photocurrent increases with the bias. The decrease of electron lifetime and photoconductive gain with the increased bias in $\mathrm{p}-\mathrm{i}-\mathrm{n}$ diodes has also been found by others. [8,9]

\section{CONCLUSION}

The transient photoconductive gain was measured with $\mathrm{p}-\mathrm{i}-\mathrm{n}, \mathrm{n}-\mathrm{i}-\mathrm{n}$ and $\mathrm{n}-\mathrm{i}-\mathrm{p}-\mathrm{i}-\mathrm{n}$ devices. For short light pulses $(<1 \mu \mathrm{sec})$, the gain was almost the same for all the devices. For rather longer light pulses ( $1 \mathrm{msec}) \mathrm{n}-\mathrm{i}-\mathrm{n}$ and $n-\mathrm{i}-\mathrm{p}-\mathrm{i}-\mathrm{n}$ devices showed higher gains than $\mathrm{p}-\mathrm{i}-\mathrm{n}$. At a dark current density of $\sim 10 \mathrm{~mA} / \mathrm{cm}^{2}$, a gain of 9 could be obtained for the short light pulses and gains more than 200 could be achieved for the

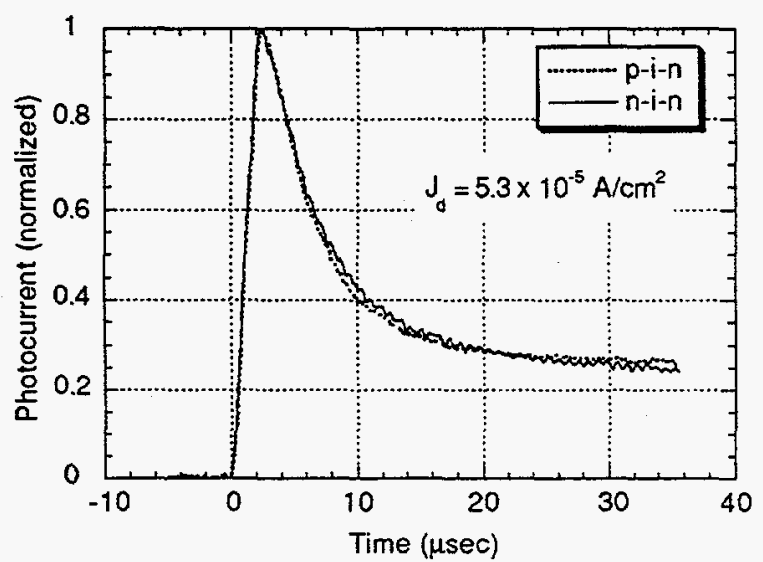

(a)

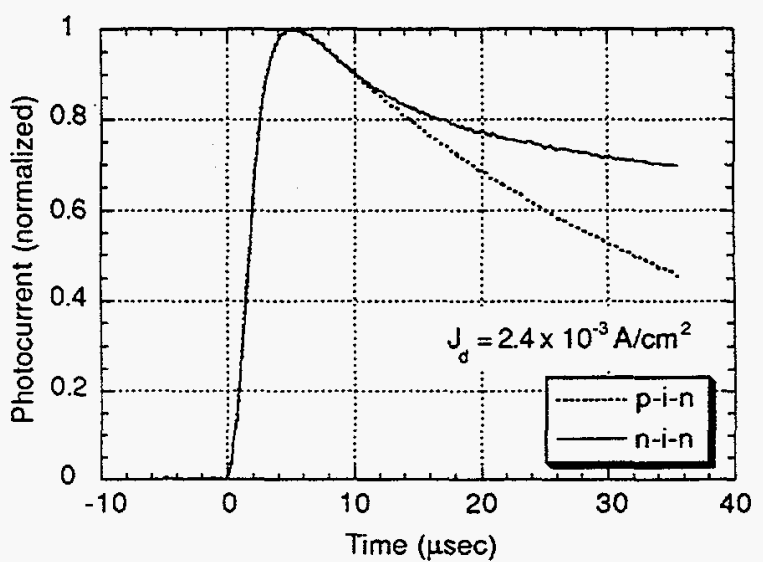

(b)

Fig. 6 The decaying photocurrent shapes of $\mathrm{p}-\mathrm{i}-\mathrm{n}$ and $\mathrm{n}-\mathrm{i}-\mathrm{n}$ devices after a short light pulse. 


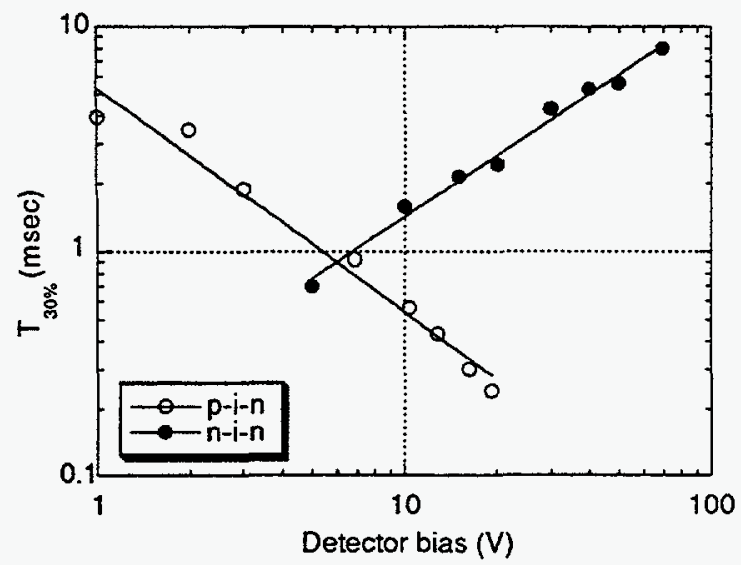

Fig. $7 \quad T_{30 \%}$ of $\mathrm{p}-\mathrm{i}-\mathrm{n}$ and $\mathrm{n}-\mathrm{i}-\mathrm{n}$ devices. $\mathrm{T}_{30 \%}$ is defined in the text.

long pulses. Single charged particle detection using photoconductive gain mechanism is expected to have higher noise level due to the higher dark current compared to the conventional methods of radiation detection. This can be, however, minimized by making pixels with small area. Work is continuing to obtain higher gain at lower dark current for the short light pulses.

\section{ACKNOWLEDGMENTS}

This work was supported by the Director, Office of Energy Research, Office of High Energy Nuclear Physics, High Energy Physics Division of U. S. Department of Energy under Contract No. DE-AC03-76SF00098.

\section{REFERENCES}

1. W. Guang-Pu, H. Okamoto and Y. Hamakawa, Jpn. J. Appl. Phys. 24, 1105 (1985)

2. V. Perez-Mendez, J. Morel, S. N. Kaplan and R. A. Street, Nucl. Instr. and Meth. A252, 478 (1987).

3. V. Perez-Mendez, in Amorphous \& Microcrystalline Semiconductor Devices, edited by J. Kanicki (Artech House, Boston, 1991), pp. 297-330.

4. I. Fujieda, G. Cho, J. Drewerey, T. Gee, T. Jing, S. N. Kaplan, V. Perez-Mendez and D. Wildermuth, IEEE Trans. Nuc. Sci. NS-38, 255 (1991).

5. H. K. Lee, J. S. Drewery, W. S. Hong, T. Jing, S. N. Kaplan, A. Mireshghi and V. Perez-Mendez, SPIE Proc. 2163, 427 (1994)

6. R. Williams and R. S. Crandall, RCA Rev. 40, 371 (1979)

7. M. Hack, M. Shur and C. C. Tsai, Appl. Phys. Lett. 54, 96 (1989)

8. F. A. Rubinelli, J. Y. Hou and S. J. Fonash, J. Appl. Phys. 73, 2548 (1993)

9. R. Vanderhaghen, R. Amokrane, D. Han and M. Silver, J. Non-Cryst. Solids 164166, 599 (1993)

10. T. Hamano, H. Ito, T. Nakamura, T. Ozawa, M. Fuse and M. Takenouchi, Jpn. J. Appl. Phys. 21, 245 (1982)

11. T. Kagawa, N. Matsumoto and K. Kumabe, Jpn. J. Appl. Phys. 21, 251 (1982)

12. R. G. Stearns and R. L. Weisfield, Appl. Optics 31, 6874 (1992)

13. A. Rose, Concepts in Photoconductivity and Allied Problems, (Interscience Publishers, New York, 1963), p. 4.

14. N. V. Joshi, Phys. Rev. B, 27, 6272 (1983) 